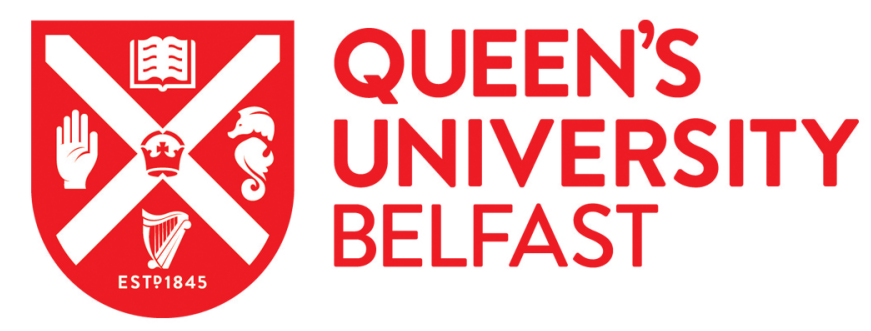

\title{
Multicenter Randomized Controlled Trial of Withdrawal of Inhaled Corticosteroids in Cystic Fibrosis
}

\author{
Balfour-Lynn, I. M., Lees, B., Hall, P., Phillips, G., Khan, M., Flather, M., \& Elborn, J. (2006). Multicenter \\ Randomized Controlled Trial of Withdrawal of Inhaled Corticosteroids in Cystic Fibrosis. American Journal of \\ Respiratory and Critical Care Medicine, 173(12), 1356-1362. https://doi.org/10.1164/rccm.200511-1808OC
}

Published in:

American Journal of Respiratory and Critical Care Medicine

Document Version:

Publisher's PDF, also known as Version of record

Queen's University Belfast - Research Portal:

Link to publication record in Queen's University Belfast Research Portal

\begin{abstract}
General rights
Copyright for the publications made accessible via the Queen's University Belfast Research Portal is retained by the author(s) and / or other copyright owners and it is a condition of accessing these publications that users recognise and abide by the legal requirements associated with these rights.
\end{abstract}

Take down policy

The Research Portal is Queen's institutional repository that provides access to Queen's research output. Every effort has been made to ensure that content in the Research Portal does not infringe any person's rights, or applicable UK laws. If you discover content in the Research Portal that you believe breaches copyright or violates any law, please contact openaccess@qub.ac.uk. 


\title{
Multicenter Randomized Controlled Trial of Withdrawal of Inhaled Corticosteroids in Cystic Fibrosis
}

\author{
Ian M. Balfour-Lynn, Belinda Lees, Pippa Hall, Gillian Phillips, Mohammed Khan, Marcus Flather, and \\ J. Stuart Elborn, on behalf of the CF WISE (Withdrawal of Inhaled Steroids Evaluation) Investigators*
}

Department of Paediatric Respiratory Medicine and Clinical Trials \& Evaluation Unit, Royal Brompton Hospital, London; National Heart \& Lung Institute, Imperial College London, London; and Adult Cystic Fibrosis Unit, Belfast City Hospital, Belfast, United Kingdom

\begin{abstract}
Rationale: Lung inflammation and injury is critical in cystic fibrosis. An ideal antiinflammatory agent has not been identified but inhaled corticosteroids are widely used despite lack of evidence.

Objectives: To test the safety of withdrawal of inhaled corticosteroids with the hypothesis this would not be associated with an earlier onset of acute chest exacerbations.

Methods: Multicenter randomized double-blind placebo-controlled trial in 18 pediatric and adult UK centers. Eligibility criteria included age $>6.0 \mathrm{yr}, \mathrm{FEV}_{1} \geqslant 40 \%$ predicted, and corticosteroid use $>3 \mathrm{mo}$. During the 2-mo run-in period, all patients received fluticasone; they then took either fluticasone or placebo for $6 \mathrm{mo}$.

Measurements and Main Results: Fluticasone group: $\mathrm{n}=84$, median age $14.6 \mathrm{yr}$, mean (SD) $\mathrm{FEV}_{1} 76 \%$ (18); placebo group: $\mathbf{n}=87$, median age $15.8 \mathrm{yr}$, mean (SD) FEV $76 \%$ (18). There was no difference in time to first exacerbation (primary outcome) with hazard ratio ( $95 \%$ confidence interval) of $1.07(0.68$ to 1.70$)$ for fluticasone versus placebo. There was no effect of age, atopy, corticosteroid dose, $\mathrm{FEV}_{1}$, or Pseudomonas aeruginosa status. There was no change in lung function or differences in antibiotic or rescue bronchodilator use. Fewer patients in the fluticasone group withdrew from the study due to lung-related adverse events ( 9 vs. $15 \%)$; with a relative risk $(95 \%$ confidence interval) of $0.59(0.23-1.48)$ fluticasone versus placebo.

Conclusions: In this study population (applicable to $40 \%$ of patients with cystic fibrosis in the UK), it appears safe to consider stopping inhaled corticosteroids. Potential advantages will be to reduce the drug burden on patients, reduce adverse effects, and make financial savings.
\end{abstract}

Keywords: antiinflammatory therapy; inhaled corticosteroids; lung diseases

Lung disease is responsible for much of the morbidity and most of the mortality in cystic fibrosis (CF). Neutrophil-dominated inflammation combined with an exaggerated host response is a major contributor to this lung injury (1). Antiinflammatory

(Received in original form November 25, 2005; accepted in final form March 21, 2006) * Investigators are listed at end of report.

Supported by grant PJ498 from UK Cystic Fibrosis Trust. GlaxoSmithKline provided fluticasone and placebo inhalers. Neither the Cystic Fibrosis Trust nor GlaxoSmithKline had any role in the study design, data collection, data analysis, data interpretation, writing of the report, or the decision to submit it for publication.

This study was presented at the 19th North American Cystic Fibrosis Conference, Baltimore MD on October 21, 2005.

Correspondence and requests for reprints should be addressed to lan M. BalfourLynn, M.D., F.R.P.C.H., Department of Paediatric Respiratory Medicine, Royal Brompton \& Harefield NHS Trust, Sydney Street, London SW3 6NP, UK. E-mail: i.balfourlynn@ic.ac.uk

This article has an online supplement, which is accessible from this issue's table of contents at www.atsjournals.org

Am J Respir Crit Care Med Vol 173. pp 1356-1362, 2006

Originally Published in Press as DOI: 10.1164/rccm.200511-18080C on March 23, 2006 Internet address: www.atsjournals.org therapy is a logical approach to slow down the inevitable deterioration in lung function, $(2,3)$ but an ideal agent has not yet been identified (4).

Corticosteroids have a wide range of antiinflammatory actions, including several important effects on neutrophils. Oral corticosteroids slow the progression of CF lung disease, but long term use is precluded by unacceptable side effects (5). A systematic review of inhaled corticosteroids (ICS) in CF revealed 10 randomized controlled trials (6 published), which had studied 293 adults and children (6). There was variable methodologic quality, and the conclusion was that there was "no evidence from existing trials to support the practice of prescribing inhaled steroids in cystic fibrosis."

While the use of ICS may be justified as a form of symptom prophylaxis for those with recurrent wheezing or concomitant asthma (7), there is little evidence to justify their routine use in $\mathrm{CF}$ lung disease. Despite this, there has been an increase in the prescribing and use in patients with CF in Europe and the United States. Databases of annual review returns have recorded the ICS use as 36\% in the United Kingdom (1994 and 1995 snapshot data) (8) and 26\% in North America (1995 snapshot data) (9). More recent data from 2001 entries showed that in the United Kingdom (CF Trust Database) $52 \%$ of children and $55 \%$ of adults were prescribed ICS, wheras in the United States (Epidemiologic Study of CF) they were given to $41 \%$ of children and $48 \%$ of adults. The concern over this increased prescribing is that ICS are not necessarily free of adverse effects, although at recommended doses they have an excellent safety record in asthmatic children (10). However, several case series have highlighted the occasional dangers of high-dose ICS causing adrenal failure in asthmatic children (10).

The widespread use of ICS in CF has made it difficult to mount a prospective trial. We therefore took an alternative approach, which was a withdrawal study in patients who were already taking ICS. Nonblinded withdrawal of ICS was used during the initial phase of the large adult Inhaled Steroids in Obstructive Lung Disease in Europe (ISOLDE) trial of ICS in chronic obstructive pulmonary disease (COPD) $(11,12)$. The aim of our study was to perform a multicenter randomized doubleblind placebo-controlled trial to test the feasibility and safety of withdrawal of ICS in children and adults with CF who were already taking them. The main hypothesis was that withdrawing ICS would not be associated with an earlier onset of acute chest exacerbations. A further hypothesis was that specific subgroups of patients (for example, those with atopy) may benefit from them, and if true, this should allow more discriminatory prescribing.

Some of the results of this study have been previously reported in an abstract (13).

\section{METHODS}

For additional detail see the expanded Methods in the online supplement.

\section{Patients}

Patients were recruited from $18 \mathrm{CF}$ centers. Eligibility criteria were a diagnosis of $\mathrm{CF}$; age over $6.0 \mathrm{yr} ; \mathrm{FEV}_{1} \geqslant 40 \%$ predicted; and use of 
ICS $\geqslant 3$ mo. Exclusion criteria were use of oral corticosteroids within the previous month or very high-dose ICS. Cases who were eligible for the trial but whom the clinician wished to continue taking ICS were entered as an open label ICS registry group.

The study was approved by the London Multi-Centre Research Ethics Committee, and all local ethics committees.

\section{Procedures}

This was a randomized double-blind placebo-controlled withdrawal study of 8-mo duration. There was a 2-mo run-in period during which all patients received fluticasone propionate via a Volumatic spacer (GlaxoSmithKline, Uxbridge, UK). If previously receiving fluticasone the dose was unchanged, but if they were previously on budesonide or beclometasone dipropionate, this was switched to fluticasone at a 2:1 ratio. Salbutamol (Ventolin accuhaler with dose counter; GlaxoSmithKline) was used as a rescue bronchodilator. Patients were randomized to continue fluticasone or start placebo using identical metered-dose inhalers via their spacer.

The criterion for early trial withdrawal was progressive deterioration, defined as sustained decline in $\mathrm{FEV}_{1}>15 \%$ despite 2 wk of oral/ intravenous antibiotics, or sustained symptoms that required restarting ICS or starting oral corticosteroids. The stopping rule for the study was evidence of harm in the placebo group, defined as an excess of patients with acute bronchospasm requiring hospitalization or oral corticosteroids.

\section{Outcome Measures}

The primary outcome was time to first respiratory exacerbation using a standard definition (14). Secondary outcomes were: (1) Decline in lung function (spirometry $\mathrm{FEV}_{1}$ and FVC). (2) New (unplanned) courses of oral or intravenous antibiotics. (3) Rescue bronchodilator usage (from accuhaler dose counter). Serious adverse events were hospitalizations other than for a pulmonary exacerbation. Prespecified subgroup analysis was performed for age, atopic status, dose of ICS, baseline $\mathrm{FEV}_{1}$; and Pseudomonas aeruginosa infection status.

\section{Randomization and Stratification}

Randomization was performed in permuted blocks of four to balance the stratifying variables and centers. Patients were stratified for age, $\mathrm{FEV}_{1}$, and atopic status. All study personnel and participants were blinded to treatment allocation. Interim analysis (blinded to group allocation) was performed on three occasions for the Data Monitoring Committee.

\section{Statistical Analysis}

A treatment withdrawal trial is not easily categorized as either a difference or a noninferiority trial. One would not expect the treatments to be identical, but rather to show that withdrawal was not associated with significant clinical deterioration or critical safety issues. Methodology for such trials is not well established, so the protocol was designed to follow a conventional model. Sample size was based on the primary outcome. We anticipated an exacerbation (event) rate of $70 \%$ in 6 mo. Proportional differences of $30 \%$ in this event rate are clinically important (reduction in event rate from 70 to $49 \%$; under a proportional hazards assumption this is equivalent to a hazard ratio of 0.56). Sample size estimates $(80 \%$ power, $\alpha=0.05)$ for an event rate of $70 \%$ indicated we would need 164 patients.

Statistical analyses were based on the intention-to-treat principle and were performed using SAS version 8.1 (SAS Institute Inc., Marlow, UK). All tests were two sided and $p$ values $<0.05$ were considered statistically significant. For the primary outcome, the event rates were compared and the hazard ratio with $95 \%$ confidence interval (CI) calculated from the Cox proportional hazard model. Wilcoxon rank sum test was used to compare percent change in lung function between the two groups. Odds ratio or relative risks with $95 \%$ CI were calculated to compare each categorical variable between the two treatment groups.

\section{RESULTS}

\section{Baseline Data}

Figure 1 shows the trial profile for recruitment and randomization (November 2001 to July 2004). Baseline characteristics of the 171 randomized patients were well matched (Table 1), but although atopic status was similar in the two groups (as expected because this was in the stratification), there were a greater proportion of asthmatics in the group assigned to fluticasone (25 vs. $9 \%)$. Table 1 also shows details of ICS therapy at the time of recruitment. There was a greater proportion taking high-dose ICS in those randomized to fluticasone ( 55 vs. $45 \%$ ). During the run-in period, $45 \%$ of patients were switched to fluticasone, with similar proportions in both groups. There was no change in lung function from the start of the study (visit 1) to start of study drug (visit 2) in either group-mean difference (95\% CI) $\mathrm{FEV}_{1}$ $+0.9 \%(-0.9$ to 2.7$)$ for fluticasone and $-1.46 \%(-3.7$ to 0.8$)$ for placebo.

\section{Primary Outcome}

There was no difference in time to first exacerbation between the groups, and intention-to-treat analysis showed a hazard ratio (95\% CI) of 1.07 (0.68 to 1.70$)$ for fluticasone versus placebo (Figure 2). Per protocol analysis gave a hazard ratio (95\% CI) of $1.10(0.70-1.75)$. By 6 mo, $49 \%$ of the fluticasone group and $46 \%$ of the placebo group had experienced at least one chest exacerbation (an absolute difference of 3\% with $95 \%$ CI of -12 to $18 \%$ and a proportional difference of $7 \%$ ). Eleven patients in the fluticasone group and 14 in the placebo group had two exacerbations whereas 5 in the fluticasone and 8 in the placebo had three or more.

\section{Prespecified Subgroup Analysis for the Primary Outcome}

Hazard ratios for time to first exacerbation for fluticasone versus placebo were not significant (using discrete variables) when analyzed by age $(p=0.8)$, atopic status $(p=0.53)$, current dose of inhaled corticosteroids $(\mathrm{p}=0.15)$, baseline $\mathrm{FEV}_{1}(\mathrm{p}=0.053)$, and $P$. aeruginosa status $(\mathrm{p}=0.24)$. When $\mathrm{FEV}_{1}$ was analyzed as a continuous covariate, it was significant for event rate with $\mathrm{p}=0.03$ (i.e., the lower the $\mathrm{FEV}_{1}$, the higher the event rate), but not significant for treatment with $\mathrm{p}=0.09$, (i.e., no difference between those on fluticasone and those on placebo). When age was analyzed as a continuous covariate it was significant for neither event rate nor treatment. Because of the imbalance in asthma between the two groups, asthma was included in the model and the adjusted hazard ratio $(95 \% \mathrm{CI})$ was $1.03(0.64$ 1.65) for fluticasone versus placebo.

\section{Secondary Outcomes}

There was no significant change in lung function over time in either group, or any difference between the two groups (Figure 3). There was no difference in the number of courses of oral or intravenous antibiotics prescribed, either in number of patients receiving them or the median number of courses per patient (Table 2). Neither was there any difference in rescue bronchodilator use, either in number of patients using them or median number of doses per patient (Table 2).

Height was measured at the start and end of the study in the pediatric patients; $\mathrm{Z}$ score was similar for the two groups at the start (Table 1), and there was no difference in growth over the 8 mo-mean (95\% CI) difference in height $\mathrm{Z}$ score between groups of 0.04 (-1.1 to 0.2 ). Microbiology testing at each visit showed that of the patients from whom $P$. aeruginosa had never been isolated before the study, only one patient (in placebo group) developed it for the first time during the study.

\section{Open Label Inhaled Corticosteroid Group}

Compared with the 171 patients that clinicians were prepared to enter into the study, the 24 patients who continued on their original ICS differed in having a greater proportion with asthma 


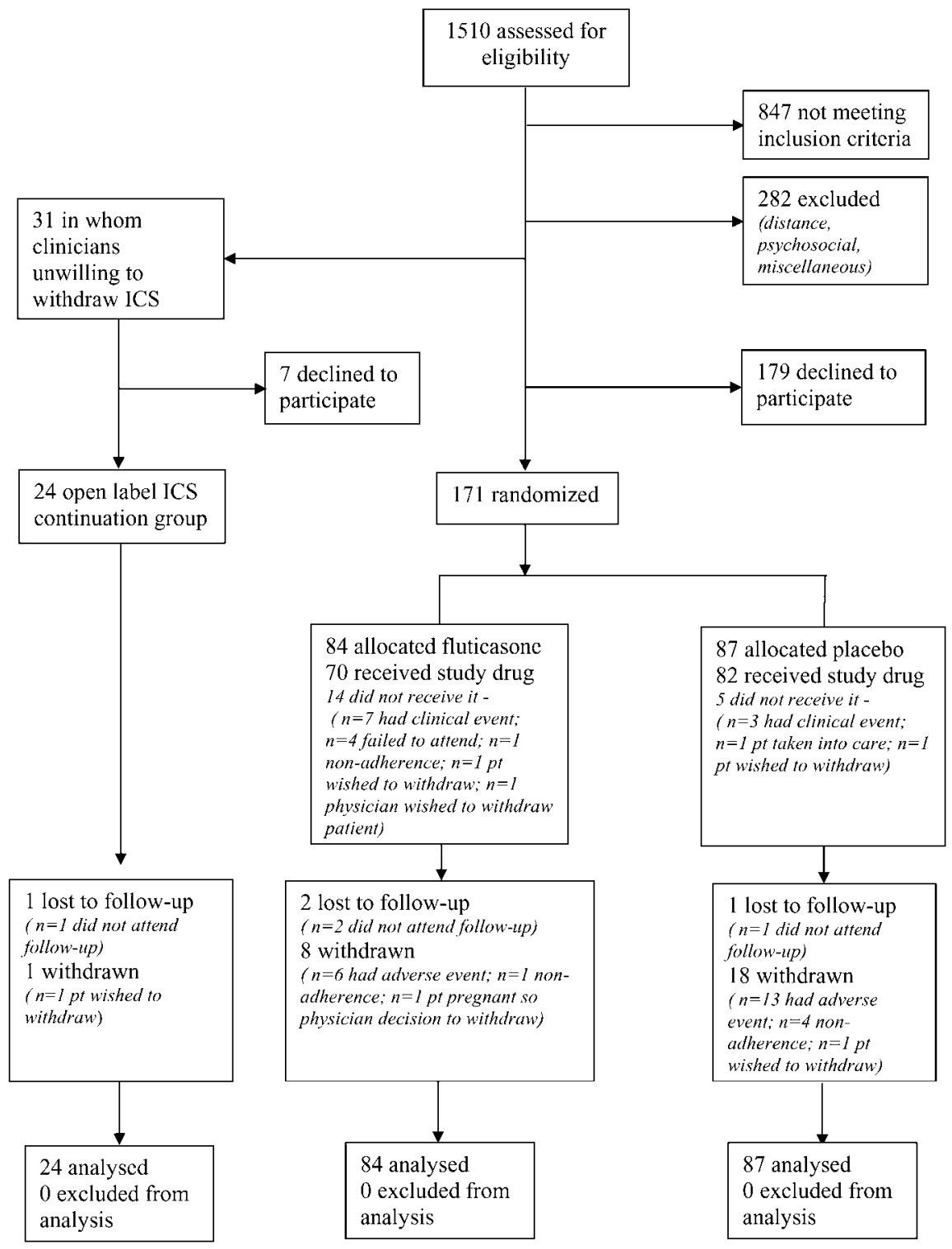

Figure 1. Trial profile.

$(\mathrm{p}<0.001)$, a greater proportion on high-dose ICS $(\mathrm{p}=0.05)$, and lower FEV $(p=0.01)$ and FVC $(p=0.06)$. Other characteristics, including atopic status, were similar (Table 1). The exacerbation rate was greater in the open label group (69\%) compared with the fluticasone group (49\%) but this was not significant $(\mathrm{p}=0.11)$. Oral antibiotics were prescribed to $88 \%$ and intravenous antibiotics to $46 \%$ of the open label group, which is higher (but not significantly) than the fluticasone group.

\section{Adverse Events and Study Withdrawals}

Total withdrawals after recruitment were the same in the two groups (24 each) (Figure 1). Of those withdrawing before the start of the study drug, seven withdrew from the fluticasone group for clinical events (five with pulmonary exacerbations, one with malaise with candida infection, and one with pancreatitis) and three withdrew from the placebo group due to clinical events (all had a pulmonary exacerbation). After the start of the study drug (visit 2), there were fewer withdrawals in the fluticasone group compared with the placebo group 10/70 (14\%) versus 19/82 (23\%). These were almost all due to lung-related adverse events $6 / 70(9 \%)$ versus $12 / 82(15 \%)$ with a relative risk (95\% CI) of fluticasone versus placebo of 0.59 (0.23-1.48). A similar proportion in both groups received oral corticosteroids for these events (7\% fluticasone group, 9\% placebo group). Lung-related adverse events simply meant protocol-defined exacerbations; withdrawal was due to a need for oral corticosteroids (5/6 fluticasone group and 7/12 placebo group) or concern from the clinician or patient that the patient was on placebo and that lack of ICS had provoked the exacerbation. The one withdrawal due to an adverse event that was not lung-related was in the placebo group and was due to facial swelling with difficulty swallowing. There were three serious adverse events in the fluticasone group (minor head injury, gallstones, intraabdominal sepsis) and none in the placebo group. Overall, there were 136 adverse events in the fluticasone group and 161 in the placebo group. For comparison of the fluticasone group versus the placebo group, they were classified as CF pulmonary symptoms (118 vs. 132), CF extrapulmonary symptoms (4 vs. 12), symptoms with no relation to CF (13 vs. 17$)$, and possible studydrug-related oral candidiasis in one patient on fluticasone. There were no deaths. 
TABLE 1. BASELINE DATA, INCLUDING INHALED CORTICOSTEROID THERAPY AT TIME OF RECRUITMENT

\begin{tabular}{|c|c|c|c|}
\hline & $\begin{array}{c}\text { Fluticasone } \\
(n=84)\end{array}$ & $\begin{array}{l}\text { Placebo } \\
(n=87)\end{array}$ & $\begin{array}{c}\text { Open label ICS } \\
\quad(n=24)\end{array}$ \\
\hline Age, yr, median (range) & $14.6(6-48)$ & $15.8(6-53)$ & $14.8(7-41)$ \\
\hline Males, \% (n) & $49(41)$ & $52(45)$ & $42(10)$ \\
\hline \multicolumn{4}{|l|}{ Genotype, \% (n) } \\
\hline$\Delta \mathrm{F} 508$ homozygous & $48(40)$ & $59(51)$ & $42(10)$ \\
\hline$\Delta \mathrm{F} 508$ heterozygous & $43(36)$ & $36(31)$ & $46(11)$ \\
\hline Other & $9(8)$ & $5(5)$ & $12(3)$ \\
\hline Body mass index, $\mathrm{kg} / \mathrm{m}^{2}$, mean (SD) & $19.9(3.7)$ & $20.1(4.0)$ & $19.3(3 \cdot 3)$ \\
\hline Height, Z score * & -0.55 & -0.39 & - \\
\hline Atopy, \% (n) & $35(29)$ & $38(33)$ & $46(11)$ \\
\hline Asthma, $\%(\mathrm{n})$ & $25(21)$ & $9(8)$ & $67(16)^{\dagger}$ \\
\hline \multicolumn{4}{|l|}{ Pseudomonas aeruginosa status, \% (n) } \\
\hline$\geqslant 2$ isolations in last $12 \mathrm{mo}$ & $62 \%(52)$ & $65 \%(56)$ & $70 \%(16)$ \\
\hline Previous isolation (not last $12 \mathrm{mo}$ ) & $27 \%(23)$ & $26 \%(22)$ & $26 \%(6)$ \\
\hline Never isolated & $11 \%(9)$ & $9 \%(8)$ & $4 \%(1)$ \\
\hline $\mathrm{FEV}_{1}$ (\% predicted), mean (SD) & $76(18)$ & $76(18)$ & $67(14)^{\dagger}$ \\
\hline FVC (\% predicted), mean (SD) & $90(16)$ & $92(18)$ & $84(13)$ \\
\hline \multicolumn{4}{|l|}{ Current type ICS, \% (n) } \\
\hline Beclometasone & $13(11)$ & $13(11)$ & $13(3)$ \\
\hline Budesonide & $32(27)$ & $32(28)$ & $25(6)$ \\
\hline Fluticasone & $55(46)$ & $55(48)$ & $63(1)$ \\
\hline \multicolumn{4}{|l|}{ Current dose of ICS, \% (n) } \\
\hline Low dose & $45(38)$ & $55(48)$ & $29(7)$ \\
\hline High dose & $55(46)$ & $45(39)$ & $71(17)^{\dagger}$ \\
\hline Length of time on ICS, yr, median (range) & $5(1-21)$ & $6(1-23)$ & $5(1-11)$ \\
\hline
\end{tabular}

High dose ICS was defined as $>800 \mu \mathrm{g} / \mathrm{d}$ budesonide or beclometasone or $>400 \mu \mathrm{g} / \mathrm{d}$ fluticasone; low dose was $\leqslant 800 \mu \mathrm{g} \mathrm{d}$ of the former and $\leqslant 400 \mu \mathrm{g} / \mathrm{d}$ of the latter.

* Height Z score (SD score below or above mean height for age and sex-matched normal population) was measured in pediatric centers only ( $n=47$ fluticasone, $n=48$ placebo).

${ }^{\dagger}$ Significantly different parameters in open label inhaled corticosteroid (ICS) group $(p<0.05)$ compared with those enrolled in the active trial $(n=171)$.

\section{DISCUSSION}

This study has shown that during the first 6 mo after stopping ICS therapy, there was no apparent impact (adverse or beneficial), on the onset of acute chest exacerbations, decline in lung function, antibiotic prescribing, or rescue bronchodilator use. Replacing the ICS with placebo was found to be safe as there was no

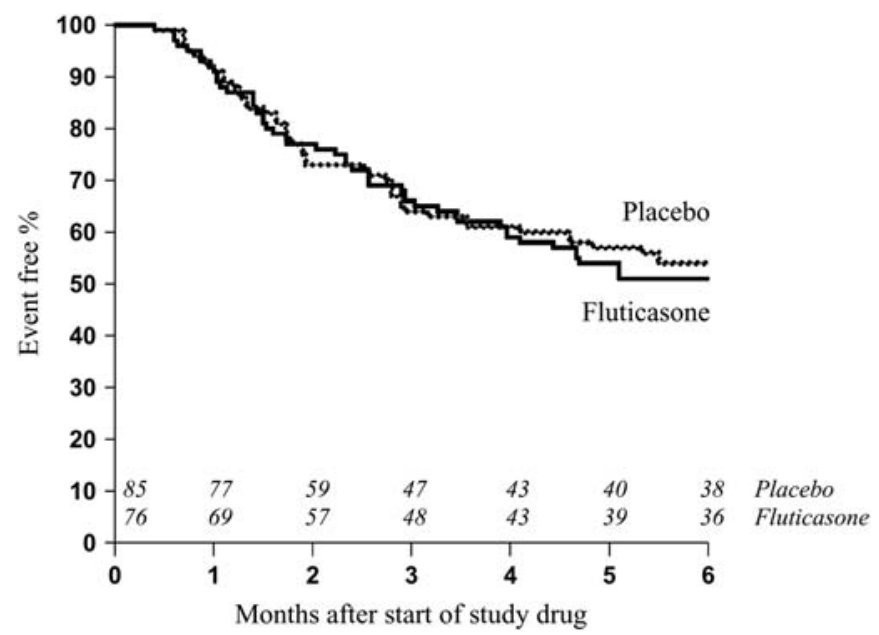

Figure 2. Kaplan-Meier plot of time to first exacerbation after start of study drug, in the fluticasone (solid) and placebo (dotted) groups. Numbers in italics are patients at risk of an event. There was no difference between the groups with a hazard ratio (95\% confidence interval- $-\mathrm{Cl})$ of 1.07 ( 0.68 to 1.70$)$ for the comparison of fluticasone with placebo. significant increase in lung-related adverse effects leading to withdrawal from the study, nor an increased need for oral corticosteroids. Many patients with CF who are on ICS may no longer need them, but caution is advised due to the nonsignificant increase in lung-related adverse effects seen in the placebo group. Data provided by the UK CF Trust Database has shown that the eligibility criteria of this study applied to almost $40 \%$ of the UK CF population (approximately 3,000 patients).

It must be stressed that we are not advocating stopping ICS in all patients, but urging clinicians to assess the need in each individual. If there is objective evidence that a patient benefited when ICS were first started, then it is likely they should be continued on ICS. With nonsignificant tests for interaction, the prespecified subgroup analysis has not provided clear information to help define who are more likely to benefit from ICS. However, there was a significant association between increased exacerbation rate and lower lung function, although this did not quite reach significance in the comparison of the fluticasone and placebo groups. There were patients eligible for the study that the clinicians were not prepared to enroll, due to a belief that they should not stop taking ICS. Their baseline data reveals factors that experienced CF clinicians believe warrant the use of ICS therapy. Compared with the patients entered into the study, they had significantly lower lung function, and significantly more were taking high-dose ICS and were thought to have "CF asthma." Although CF asthma is difficult to define (7), investigators provided their own definitions, which included reversible obstructive airways, peak flow variability, response to antiasthma therapy, and recurrent wheeze, particularly if symptoms are not accompanied by an obvious infective exacerbation; a family or personal history of atopy supported the diagnosis. Although the number of $\mathrm{CF}$ asthmatic patients in our study does not allow us 

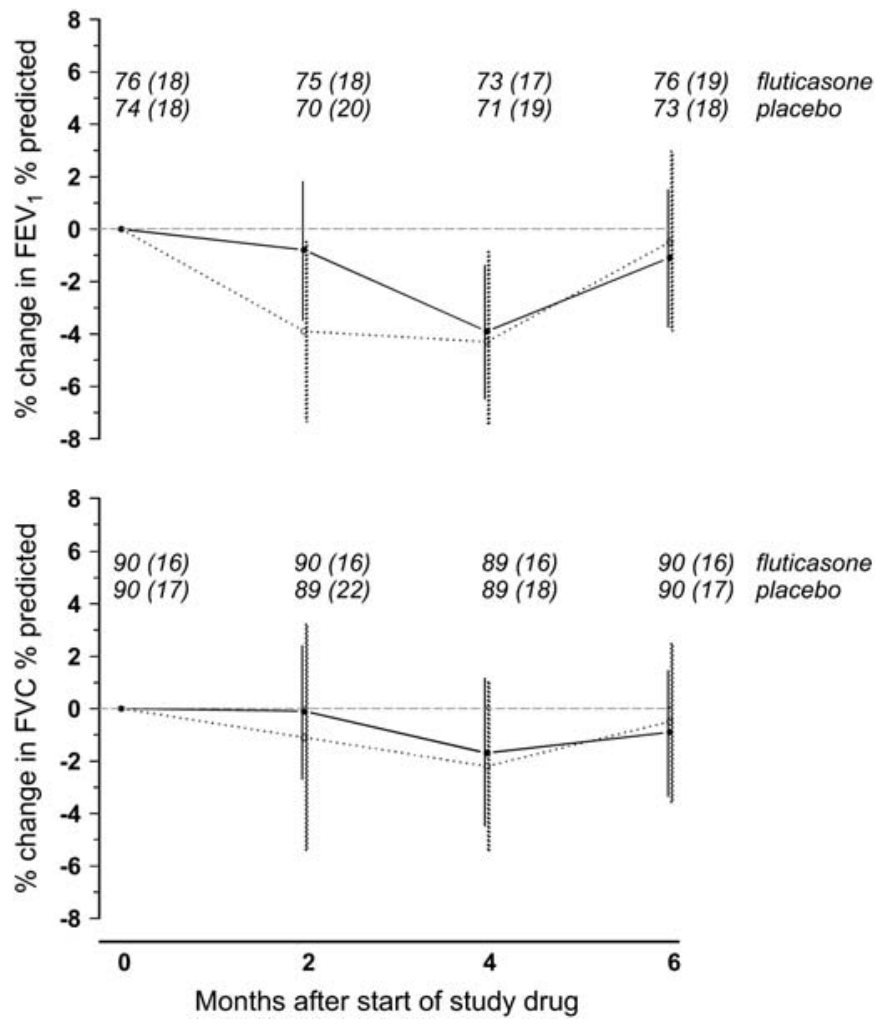

Figure 3. Mean percentage change in lung function ( $\mathrm{FEV}_{1}$ and $\mathrm{FVC} \%$ predicted) in fluticasone (solid line) and placebo (dotted line) groups. Time is months after start of study drug. Also shown are $95 \% \mathrm{Cl}$ (fluticasone group, solid line; placebo group, dotted line). Numbers in italics are mean (SD) \% predicted $\mathrm{FEV}_{1}$ and FVC. Dashed line represents zero change. There was no significant decline in lung function in either group, nor any difference between the two groups ( $p=0.51$ for $\%$ change $\mathrm{FEV}_{1}$, and $\mathrm{p}=0.72$ for \% change FVC, Wilcoxon rank sum test).

to make firm conclusions, our findings suggest that many of these patients can also have their ICS dose reduced safely. However, we would be more reluctant to withdraw ICS in a CF patient who genuinely had accompanying asthma. The issue of the interaction of long-acting $\beta_{2}$-agonists with ICS is another issue that may need to be addressed. We did not measure bronchial reactivity as it is a variable measure in CF (especially in children) and is not particularly useful for diagnosing CF asthma (7).
Are there any problems with the study that mean its conclusions should be doubted? Recruitment was open to potential selection bias, with the concern that clinicians only enrolled patients they thought would not deteriorate off ICS. However in a withdrawal trial it would be unethical to stop a therapy that was believed to be benefiting a patient. Follow-up of patients that clinicians decided not to recruit has provided information on their characteristics and outcomes. The study was powered for the primary outcome on the assumption that 164 patients were required for a $70 \%$ exacerbation rate, but the overall exacerbation rate for subjects turned out to be $47 \%$. In retrospect, the protocol definition of an exacerbation was too strict (14), as most clinicians would not wait for four criteria to be satisfied before instituting therapy. For example, an increase in purulent sputum accompanied by a fall in $\mathrm{FEV}_{1}$ of more than $10 \%$ would almost always lead to a course of antibiotics on the assumption the patient had a chest exacerbation (even though only two criteria of the study definition were satisfied). Only $19 \%$ of subjects received neither oral nor intravenous antibiotics, so it can be assumed that up to $81 \%$ of subjects actually had a chest exacerbation, as this is the usual cause for prescription of a new course of antibiotics. This is supported by the finding that only $11 / 123(9 \%)$ of patients receiving oral antibiotics were prescribed them for viral upper respiratory tract infections, whereas all intravenous antibiotics were for chest exacerbations. We would recommend a different definition be used for future trials, perhaps the one derived from the North American Epidemiologic Study of CF (ESCF) data, which for patients 6 yr or older has suggested three out of four of decreased $\mathrm{FEV}_{1}$, increased cough frequency, new crackles, and haemoptysis (15). In addition, the patients in the trial on which we based power calculations had lower lung function than in our trial $\left(20 \%\right.$ had $\mathrm{FEV}_{1}<40 \%$, which was an exclusion criterion in our study). Despite our lower than expected exacerbation rate, the $95 \%$ CI around the hazard ratios and the fact the results exclude hazard ratios as large as that prespecified (0.56) in either direction would indicate that a type II error has not lead to our finding that there was no difference in outcomes between the two groups. Although our study had a lower power than originally planned, we believe we have effectively excluded an important clinical difference. Furthermore, we do not believe that any differences in withdrawal rate from pulmonary adverse events between the two groups biased the study results due to differential censoring, as everyone withdrawing for this reason still fulfilled the primary outcome as they had had an exacerbation.

This study supports the conclusion from the Cochrane review that there is evidence of neither benefit nor harm (6). The lack

TABLE 2. SECONDARY OUTCOMES: USE OF ORAL/INTRAVENOUS ANTIBIOTICS, AND RESCUE BRONCHODILATORS

\begin{tabular}{|c|c|c|c|}
\hline & $\begin{array}{l}\text { Fluticasone } \\
(n=84)\end{array}$ & $\begin{array}{r}\text { Placebo } \\
(n=87)\end{array}$ & $\begin{array}{l}\text { Odds Ratio* } \\
(95 \% \mathrm{Cl})\end{array}$ \\
\hline \multicolumn{4}{|l|}{ Oral antibiotics } \\
\hline Patients prescribed new courses, \% (n) & $74(62)$ & $78(68)$ & $0.96(0.81-1.12)$ \\
\hline Median (IQR) number of courses per patient (in those who received them) & $2(1-3)$ & $2(1-3)$ & \\
\hline \multicolumn{4}{|l|}{ Intravenous antibiotics } \\
\hline Patients prescribed new courses, \% (n) & $38(32)$ & $38(33)$ & $1.02(0.69-1.50)$ \\
\hline Median (IQR) number of courses per patient (in those who received them) & $1(1-2)$ & $1(1-2)$ & \\
\hline Patients who received no new courses of oral or intravenous antibiotics, $\%$ (n) & $18(15)$ & $20(17)$ & \\
\hline \multicolumn{4}{|l|}{ Rescue bronchodilators } \\
\hline Patients using, \% (n) & $50(42)$ & $61(61)$ & $0.87(0.72-1.07)$ \\
\hline Median (IQR) number of doses per patient (in those who used them) & $56(20-133)$ & $66(13-199)$ & \\
\hline
\end{tabular}

* Odds ratios $(95 \% \mathrm{Cl})$ are shown for fluticasone versus placebo.

Definition of abbreviation: IQR = interquartile range. 
of proven benefit of ICS may be because clinical trials have failed to provide the evidence for a benefit that does exist. The published trials of ICS have a number of flaws, which include small subject numbers, short treatment periods, inadequate drug dosages, and in one case lack of a placebo group (6). The alternative view is that benefit has not been proven because there is no benefit, and if that is the case, why might that be? Delivering inhaled drugs in sufficient quantities to the airways blocked by viscous mucus may be a factor. Poor inhaler technique, especially in children, can also be a problem. More relevant may be the nature of the airway inflammation in CF. It is predominantly neutrophilic and for other airway conditions in which neutrophils predominate, for example, severe asthma (16) and acute bronchiolitis (17), corticosteroids are also not particularly effective (18, 19). Although there is proven benefit in certain aspects of COPD management, (20), a biopsy study showed that 3 mo of fluticasone did not reduce the neutrophilic inflammation, despite improvement in symptoms and exacerbation rate (21). Budesonide and fluticasone, and to a lesser extent beclometasone, have been shown to prolong neutrophil survival by inhibiting apoptosis, so it might be that ICS are even promoting inflammation in $\mathrm{CF}$ airways (22). Conversely, ICS are particularly effective in mild to moderate asthma, with its largely eosinophilic inflammation (16), and ICS enhance apoptosis and the subsequent disposal of eosinophils (23).

Some clinicians take the view that ICS should be used anyway, because there are theoretical reasons why they might be useful and there is no apparent evidence of harm (6). Although it is true that they have been used safely for decades in many thousands of asthmatics, this view cannot be supported, especially with highdose ICS (note that $52 \%$ of patients in this study were on 1,000 $\mu \mathrm{g} / \mathrm{d}$ or more beclometasone equivalent). It is increasingly recognized that ICS can lead to significant symptoms related to adrenal suppression (24). There have also been reports of children and adults with $\mathrm{CF}$ who developed adrenal insufficiency and sometimes Cushing's syndrome while taking ICS (400-1200 $\mu \mathrm{g} / \mathrm{d})$ together with itraconazole for allergic bronchopulmonary aspergillosis, due to cytochrome P450 inhibition (25-27). Growth is also a concern in children on ICS $(28,29)$, and an unpublished study from Belgium showed a significant slowing in linear growth in children with $\mathrm{CF}$ on $1,000 \mu \mathrm{g} / \mathrm{d}$ fluticasone for $1 \mathrm{yr}$ (personal communication, K. De Boeck). There was no difference in growth velocity in the 6 mo of our study among the pediatric patients who were on ICS compared with those who stopped. The Lung Health Study II has revealed that inhaled triamcinolone acetonide given to middle aged and elderly patients with mild to moderate COPD leads to an increased incidence of skin bruising and impaired skin healing, as well as loss of bone mineral density after 3 yr of treatment $(30,31)$. Concern has been expressed about promotion of infection, due to an apparent increase in new $P$. aeruginosa acquisition, in an unpublished but well publicized small study of ICS that was halted prematurely (32); because of the small numbers and short time frame it is difficult to know whether the findings of this study were valid. However, a retrospective study of 83 patients under $10 \mathrm{yr}$ found no significant effect of the use of ICS on the risk of early $P$. aeruginosa acquisition, even for those on higher doses (33). Finally, in a UK General Practice Research Database survey of more than 200,000 people aged 3-90 yr, there seems to be a slight increased risk of cataracts in those taking ICS, but only for those aged over 40 (34). There is no information in CF but it is unlikely to be a problem considering the age distribution. It can be seen therefore, that there needs to be proper justification to prescribe ICS, and especially at high doses, as, although safety is likely to be acceptable in $\mathrm{CF}$, if genuine benefit has not been proven then the risk-benefit ratio swings toward risk, however small that may be.

We are not aware of any other studies that have taken the approach of withdrawing a therapy in patients with CF. It is an approach that has been used in studying ICS and long acting $\beta_{2}$-agonists in COPD $(12,35-37)$. Although some patients declined to participate in the trial, for most the reason was not reluctance to stop a drug they had been using for a while, and in fact most were enthusiastic at the prospect of reducing their daily medications. Polypharmacy is a real problem for patients with CF, especially those with more severe disease, and it is likely that as new drugs are started, others are stopped by the patients. Despite this, clinicians tend to add on more treatments without stopping those that do not seem to be making a difference. It is probable that those who did not wish to stop ICS were those who felt they had benefited from them, and also those who were stable and did not want to change anything.

In conclusion, this study has shown that stopping ICS is not harmful for patients with $\mathrm{CF}$ who have been taking them for some years. It is likely that the majority of patients taking them no longer need to do so. We would advocate that the prescribing practice of ICS in a CF patient become more like that for an asthmatic. Justification is needed to start them, reassessment is necessary to see whether they are having an effect (particularly on any tight cough or wheeze), and consideration is always given to reducing the dose or stopping them altogether. We are not suggesting ICS should be stopped in all patients but are unable from this study to offer clear guidance as to who might best benefit. Nevertheless, baseline data from our open label group has indicated the sort of patients that experienced CF specialists believe benefit the most. This study has not proven whether starting ICS is beneficial in CF; nor has it answered whether ICS may be beneficial in reducing lung inflammation or slowing the rate of decline in lung function when taken long term. All of these questions would need long, large studies to answer them. However it is hoped this study will lead to a reduction in unnecessary ICS prescribing, which in turn will reduce the drug burden placed on patients, reduce potential adverse effects, and save money for the health services.

Conflict of Interest Statement: None of the authors has a financial relationship with a commercial entity that has an interest in the subject of this manuscript.

Acknowledgment: The authors thank the Cystic Fibrosis Trust Clinical Trials Advisory Group for helpful suggestions for trial design, GlaxoSmithKline for providing fluticasone and placebo inhalers, the Cystic Fibrosis Trust Database for 2001 data on use of corticosteroids among UK patients, and all the patients and their families for their time and enthusiasm in participating in the study.

\section{Trial Steering Committee}

C. Dezateux (Chair), D. Ashby, I.M. Balfour-Lynn, S. Elborn, D. Empey, B. Lees, M. Flather, C. Wallis, S. Walters.

\section{Independent Data Monitoring Committee}

A. Thomson (Chair), S. MacKenzie, T. Cole. Preparation of data for committee by D. Wang.

\section{Local Investigators and Pharmacists (Number of Enrolled Patients)}

Adult units: Royal Brompton Hospital (23) D. Geddes, M. Hodson, S. Scott, V. Teli; Birmingham Heartlands Hospital (15) R. Bangur, D. Chambers, D. Honeybourne, J. Lyons, D. Stableforth; Belfast City Hospital (14) J.S. Elborn, L. Hamilton, S.J. Hornsby, J. Philips, A. Rosbotham; Gartnavel General Hospital Glasgow (11) S. Bicknell, S. Hempsey, A. Smith, S. Sriram, B. Stack, J. Young; Wythenshawe Hospital Manchester (10) S. Bailey, A. Jones, A. McSorley, A. Orr, J. Redfern, D. Riley, A.K. Webb; Seacroft Hospital Leeds (6) S. Conway, C. Etherington, N. Purcell; Bristol Royal Infirmary (5) L. Ball, N. Jarad, E. Smith; Papworth Hospital Cambridge (2) D. Bilton, E. Gunn, J. Redpath; Northern General Hospital Sheffield (1) Y. Davenport, F. Edenborough, B. Kumar, A. Rogers, K. Ryalls. Pediatric units: Royal Brompton Hospital (31) I.M. Balfour-Lynn, A. Bush, J.C. Davies, J. Francis, M. Rosenthal, P. Hall, G. Phillips, V. Teli; Birmingham Children's Hospital (21) G. Amison, J. 
Clarke, M. Desai, C. Norton, P. Weller; Royal Victoria Infirmary Newcastle (12) J. Bloomer, J. Gilroy, C. O'Brien, A. Sewell, C. Sharpe, D. Spencer; Royal Liverpool Children's Hospital (11) J. Couriel, C. Doyle, P. Hayes, D. Heaf, L. Heaf, R. Smyth, K. Southern; St James' Hospital Leeds (9) K. Brownlee, S. Conway, H. Cunliffe; Bristol Royal Hospital for Children (8) L. Ball, S. Langton-Hewer, E. Smith, H. Thomas; Royal Belfast Hospital for Sick Children (7) Z. Abdelrahim, J. Bell, A. Leavy, M. McFarland, A. Millar, H. Mills, M. Mitchell, J. Murray, A. Reid, A. Watson; Queen Mary's Hospital for Children St Helier (5) R. Chavasse, L. McGraw, K. Olejnik; Royal Hospital for Sick Children Glasgow (4) J. Bledings, A.M. Devenny, J.Y. Paton.

\section{Clinical Trials and Evaluation Unit, Royal Brompton Hospital}

M. Flather, B. Lees, F. Nugara.

\section{Members of 1999 Planning Workshop}

I.M. Balfour-Lynn, P. Calverley, C. Dezateux, J.S. Elborn, D. Geddes, B. Lees, R. Smyth.

\section{References}

1. Chmiel JF, Berger M, Konstan MW. The role of inflammation in the pathophysiology of CF lung disease. Clin Rev Allergy Immunol 2002; 23:5-27.

2. Konstan MW, Davis PB. Pharmacological approaches for the discovery and development of new anti-inflammatory agents for the treatment of cystic fibrosis. Adv Drug Deliv Rev 2002;54:1409-1423.

3. Koehler DR, Downey GP, Sweezey NB, Tanswell AK, Hu J. Lung inflammation as a therapeutic target in cystic fibrosis. Am J Respir Cell Mol Biol 2004;31:377-381.

4. Hilliard TN, Balfour-Lynn IM. Anti-inflammatory agents - a clinical perspective. In: Bush A, Alton E, Davies J, Griesenbach U, Jaffe A, editors. Progress in respiratory research, Vol 34. Cystic fibrosis in the 21st century. Basel: Karger; 2005. pp.187-194.

5. Cheng K, Ashby D, Smyth R. Oral steroids for cystic fibrosis. Cochrane Database Syst Rev 1999;4:Art. No: CD000407. DOI: 10.1002/14651858. CD000407.

6. Balfour-Lynn I, Walters S, Dezateux C. Inhaled corticosteroids for cystic fibrosis. Cochrane Database Syst Rev 2000;1:Art. No: CD001915. DOI: 10.1002/14651858.CD001915.

7. Balfour-Lynn IM, Elborn JS. "CF asthma": what is it and what do we do about it? Thorax 2002;57:742-748.

8. Koch C, McKenzie SG, Kaplowitz H, Hodson ME, Harms HK, Navarro J, Mastella G. International practice patterns by age and severity of lung disease in cystic fibrosis: data from the Epidemiologic Registry of Cystic Fibrosis (ERCF). Pediatr Pulmonol 1997;24:147-154.

9. Konstan MW, Butler SM, Schidlow DV, Morgan WJ, Julius JR, Johnson CA. Patterns of medical practice in cystic fibrosis: part II. Use of therapies. Investigators and Coordinators of the Epidemiologic Study of Cystic Fibrosis. Pediatr Pulmonol 1999;28:248-254.

10. Russell G. The use of inhaled corticosteroids during childhood: plus ça change.... Arch Dis Child 2004;89:893-895.

11. Burge PS, Calverley PM, Jones PW, Spencer S, Anderson JA, Maslen TK. Randomised, double blind, placebo controlled study of fluticasone propionate in patients with moderate to severe chronic obstructive pulmonary disease: the ISOLDE trial. BMJ 2000;320:1297-1303.

12. Jarad NA, Wedzicha JA, Burge PS, Calverley PMA. An observational study of inhaled corticosteroid withdrawal in stable chronic obstructive pulmonary disease. ISOLDE Study Group. Respir Med 1999;93:161166.

13. Balfour-Lynn IM, Lees B, Hall P, Phillips G, Khan M, Flather M, Elborn S. CF WISE -Multicentre randomised controlled trial of withdrawal of inhaled corticosteroids. CF WISE Investigators. Pediatr Pulmonol 2005;Suppl 28:123-124.

14. Fuchs HJ, Borowitz DS, Christiansen DH, Morris EM, Nash ML, Ramsey BW, Rosenstein BJ, Smith AL, Wohl ME. Effect of aerosolized recombinant human DNase on exacerbations of respiratory symptoms and on pulmonary function in patients with cystic fibrosis. The Pulmozyme Study Group. N Engl J Med 1994;331:637-642.

15. Rabin HR, Butler SM, Wohl ME, Geller DE, Colin AA, Schidlow DV, Johnson CA, Konstan MW, Regelmann WE; Epidemiologic study of cystic fibrosis: pulmonary exacerbations in cystic fibrosis. Pediatr Pulmonol 2004;37:400-406.

16. Wenzel SE, Szefler SJ, Leung DY, Sloan SI, Rex MD, Martin RJ. Bronchoscopic evaluation of severe asthma: persistent inflammation associ- ated with high dose glucocorticoids. Am J Respir Crit Care Med 1997; 156:737-743.

17. Kim CK, Chung CY, Choi SJ, Kim DK, Park Y, Koh YY. Bronchoalveolar lavage cellular composition in acute asthma and acute bronchiolitis. J Pediatr 2000;137:517-522.

18. Green RH, Brightling CE, Woltmann G, Parker D, Wardlaw AJ, Pavord ID. Analysis of induced sputum in adults with asthma: identification of subgroup with isolated sputum neutrophilia and poor response to inhaled corticosteroids. Thorax 2002;57:875-879.

19. Patel H, Platt R, Lozano JM, Wang EEL. Glucocorticoids for acute viral bronchiolitis in infants and young children. Cochrane Database Syst Rev 2004;3:Art. No.: CD004878. DOI: 10.1002/14651858.CD004878.

20. National Collaborating Centre for Chronic Conditions. Chronic obstructive pulmonary disease: national clinical guideline for management of chronic obstructive pulmonary disease in adults in primary and secondary care. Thorax 2004 Feb; Suppl 1:1-232.

21. Hattotuwa KL, Gizycki MJ, Ansari TW, Jeffery PK, Barnes NC. The effects of inhaled fluticasone on airway inflammation in chronic obstructive pulmonary disease: a double-blind, placebo-controlled biopsy study. Am J Respir Crit Care Med 2002;165:1592-1596.

22. Zhang X, Moilanen E, Kankaanranta H. Beclomethasone, budesonide and fluticasone propionate inhibit human neutrophil apoptosis. Eur J Pharmacol 2001;431:365-371.

23. Walsh GM, Sexton DW, Blaylock MG. Corticosteroids, eosinophils and bronchial epithelial cells: new insights into the resolution of inflammation in asthma. $J$ Endocrinol 2003;178:37-43.

24. Todd GR, Acerini CL, Ross-Russell R, Zahra S, Warner JT, McCance D. Survey of adrenal crisis associated with inhaled corticosteroids in the UK. Arch Dis Child 2002;87:457-461.

25. Skov M, Main KM, Sillesen IB, Muller J, Koch C, Lanng S. Iatrogenic adrenal insufficiency as a side-effect of combined treatment of itraconazole and budesonide. Eur Respir J 2002;20:127-133.

26. Parmar JS, Howell T, Kelly J, Bilton D. Profound adrenal suppression secondary to treatment with low dose inhaled steroids and itraconazole in allergic bronchopulmonary aspergillosis in cystic fibrosis. Thorax 2002;57:749-750.

27. Main KM, Skov M, Sillesen IB, Dige-Petersen H, Muller J, Koch C, Lanng S. Cushing's syndrome due to pharmacological interaction in a cystic fibrosis patient. Acta Paediatr 2002;91:1008-1011.

28. Sharek PJ, Bergman DA. The effect of inhaled steroids on the linear growth of children with asthma: a meta-analysis. Pediatrics 2000;106:e8.

29. Price J, Hindmarsh P, Hughes S, Efthimiou J. Evaluating the effects of asthma therapy on childhood growth: what can be learnt from the published literature? Eur Respir J 2002;19:1179-1193.

30. Tashkin DP, Murray HE, Skeans M, Murray RP. Skin manifestations of inhaled corticosteroids in COPD patients: results from Lung Health Study II. Chest 2004;126:1123-1133.

31. Scanlon PD, Connett JE, Wise RA, Tashkin DP, Madhok T, Skeans M, Carpenter PC, Bailey WC, Buist AS, Eichenhorn M, et al.; Lung Health Study Research Group. Loss of bone density with inhaled triamcinolone in Lung Health Study II. Am J Respir Crit Care Med 2004;170:1302-1309.

32. Schmidt J, Davidson AGF, Seear M, Wong LTK, Peacock D, Gravelle A, Menon K, Cimolai N, Speert DP. Is the acquisition of Pseudomonads in cystic fibrosis patients increased by use of inhaled corticosteroids? Unexpected results from a double blind placebo controlled study. Pediatr Pulmonol 1997;Suppl 14:293-294.

33. Minicucci L, Severi G, Cresta L, Giannattasio A, Lorini R, Haupt R. Impact of inhaled corticosteroids on the risk of early Pseudomonas aeruginosa acquisition in cystic fibrosis. Acta Paediatr 2003;92:684-687.

34. Jick SS, Vasilakis-Scaramozza C, Maier WC. The risk of cataract among users of inhaled steroids. Epidemiology 2001;12:229-234.

35. O'Brien A, Russo-Magno P, Karki A, Hiranniramol S, Hardin M, Kaszuba M, Sherman C, Rounds S. Effects of withdrawal of inhaled steroids in men with severe irreversible airflow obstruction. Am J Respir Crit Care Med 2001;164:365-371.

36. van der Valk P, Monninkhof E, van der Palen J, Zielhuis G, van Herwaarden C. Effect of discontinuation of inhaled corticosteroids in patients with chronic obstructive pulmonary disease: the COPE study. Am J Respir Crit Care Med 2002;166:1358-1363.

37. Wouters EF, Postma DS, Fokkens B, Hop WC, Prins J, Kuipers AF, Pasma HR, Hensing CA, Creutzberg EC. Withdrawal of fluticasone propionate from combined salmeterol/fluticasone treatment in patients with COPD causes immediate and sustained disease deterioration: a randomised controlled trial. COSMIC Study Group. Thorax 2005;60: 480-487. 